\title{
Effect of Applied Voltage on Tool Wear in Cutting Nickel-base Superalloy
}

\author{
Hui Wang ${ }^{1,2, a}$, Fusheng $\mathrm{Ni}^{1,2, b}$, Jingjing Liu' ${ }^{1}$, Runze $\mathrm{Yu}^{1}$ \\ ${ }^{1}$ College of Mechanical and Electrical Engineering, Hohai University, Changzhou, CHN \\ ${ }^{2}$ Engineering Research Center of Dredging Technology of Ministry of Education, \\ Hohai University, Changzhou, CHN \\ awhui1268@aliyun.com, bushengni@163.com
}

Keywords: Tool wear, Applied voltage, Adhesive wear, Ni-based superalloy

\begin{abstract}
The machinability of Nickel-based superalloy GH4169 is poor, in order to improve machining efficiency, reduce costs, it is necessary to study the various factors that affect the tool wear. In this paper.The tool wear tests were carried out to investigate the effect of an externally applied voltage on insert flank wear in turning of Ni-based superalloy GH4169 with coated carbide tool YBG202. Flank wear morphology was observed and the VB values were measured. The result showed that the applied voltage affected the tool wear obviously, When the insert was no externally voltage applied, the flank wear was least, when the insert was cathode, the flank wear was lower than when the insert was anode. The insert wear increased as applied voltage increased. The externally applied voltage accelerated the tool wear due to serious adhesive and abrasive wear, which leaded to the cutting efficiency decreased and cost increased, so it should try to avoid applied voltage when machining nickel-based superalloy.
\end{abstract}

\section{Introduction}

Nickel-based superalloy GH4169 is widely employed in the aerospace industry, in particular in the hot sections of gas turbine engines, due to their high-temperature strength and high corrosion resistance. As a kind of difficult-to-cut materials, the machinability of nickel-based superaloy are poor, especially the high cutting force and cutting temperature, short tool life and poor quality of the machined surface[1].In order to improve machining efficiency and reduce costs, it is necessary to study the factors that affect tool wear.

As we all know, the additional current and voltage will be produced in cutting process, which affect the cutting process. A. Gangopadhyay [2-3]and Yamamoto[4] investigated the friction and wear behavior of a steel pair and milling process when an electric current was passed through the contact. It observed that friction and wear behavior of two components sliding against each other can be greatly influenced by an externally applied electrostatic field or electric current.Tool wear were reduced through an externally applied electric current in milling process with uncoated carbide milling inserts to machine AISI 4140 pre-heat treated steel.

The objectives of this study were to investigate whether it can reduce the wear through an externally applied voltage in machining process. Therefore, in this paper, the effect of externally applied voltage on tool wear in cutting nickel-base superalloy was studied. The tool wear tests will be carry out.

\section{Cutting test}

Machine, Tool and Materials. The experiment was set up on a universal turning machine CA6140 with a vertical milling head, powered by a $7.5 \mathrm{Kw}$ electric motor giving a speed range of $10 \sim 1400 \mathrm{rev} / \mathrm{min}$ and a feed range of $0.014 \sim 3.16 \mathrm{~mm} / \mathrm{rev}$.

The inserts is coated carbide tool YBG202 with MT-TiCN, $\mathrm{A}_{2}{ }_{2} \mathrm{O}_{3}$ and TiN coated. The geometric parameters of tool are shown in Table 1. 
Table 1 Tool geometry parameterss

\begin{tabular}{ccccccc}
\hline$\gamma_{\mathrm{o}}$ & $\alpha_{\mathrm{o}}$ & $\kappa_{\mathrm{r}}$ & $\kappa_{\mathrm{r}}{ }^{\prime}$ & $\lambda_{\mathrm{s}}$ & $\alpha_{\mathrm{o}}{ }^{\prime}$ & $r_{\varepsilon}$ \\
\hline $14^{\circ}$ & $6^{\circ}$ & $75^{\circ}$ & $15^{\circ}$ & $-6^{\circ}$ & $6^{\circ}$ & $0.5 \mathrm{~mm}$ \\
\hline
\end{tabular}

Ni-based superalloy GH4169 is selected as workpiece material in the experiments. Cutting test was performed on precipitation with a bar. Chemical composition of the material is given in Table 2 and the physical and mechanical properties of GH4169 are shown in Table 3, respectively.

Table 2 Chemical components of the materials used $\left(W_{t}\right) \%$

\begin{tabular}{ccccccccc}
\hline $\mathrm{Ni}$ & $\mathrm{Cr}$ & $\mathrm{Nb}$ & $\mathrm{Mo}$ & $\mathrm{Ti}$ & $\mathrm{C}$ & $\mathrm{Al}$ & $\mathrm{Si}$ & $\mathrm{Mn}$ \\
\hline 51.75 & 17.00 & 5.11 & 2.93 & 1.04 & 0.042 & 0.41 & 0.21 & 0.03 \\
\hline
\end{tabular}

Table 3 Physical and mechanical properties of the materials used

\begin{tabular}{ccccc}
\hline $\begin{array}{c}\text { Yield strength } \\
\sigma_{s}(\mathrm{MPa})\end{array}$ & $\begin{array}{c}\text { Tensile strength } \\
\sigma_{b}(\mathrm{MPa})\end{array}$ & $\begin{array}{c}\text { Elongation } \\
\delta(\%)\end{array}$ & $\begin{array}{c}\text { Cross-section contraction } \\
\text { ratio }\end{array}(\%)$ & Hardness \\
\hline 1260 & 1430 & 24 & 40 & HBS \\
\hline
\end{tabular}

Experimental system. The experimental system was shown in Fig. 1and Fig2. The cutting test was proposed in single-factor method. The cutting force is measured by piezoelectric dynamometer and Charge Amplifier YE5850 produced by Dalian University of Technology,China. The tool wear VB was measured by CCD microscope showed in Fig.3.

The device of

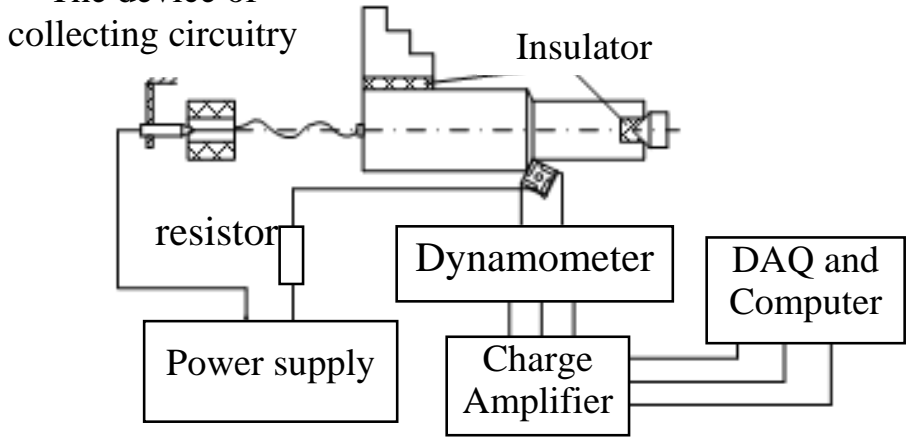

Fig.1 The Schematic illustration of the experimental system

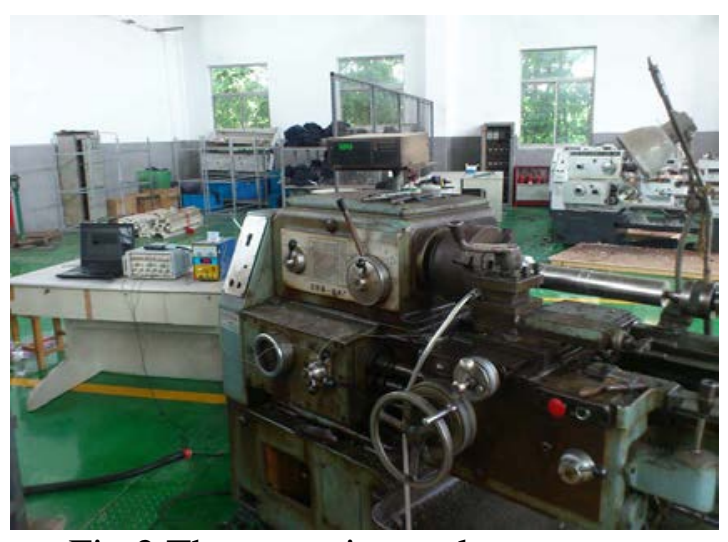

Fig.2 The experimental system

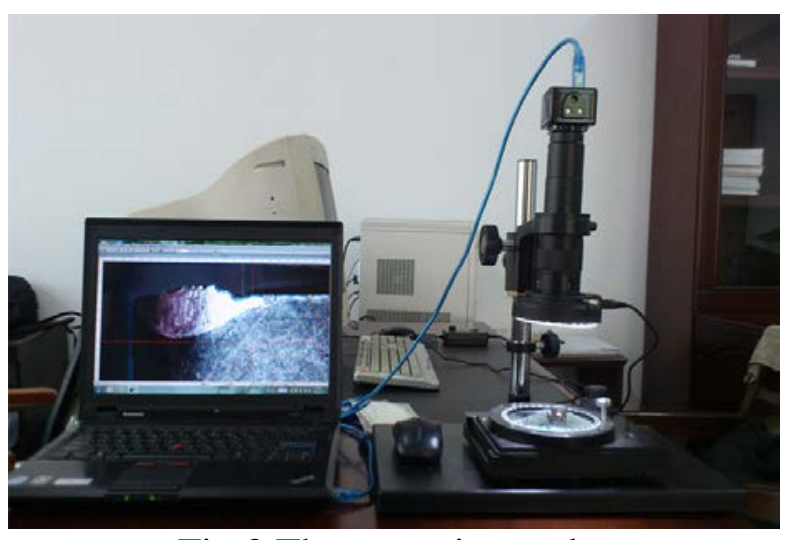

Fig.3 The experimental system 
One output of the dc power supply was connected to the workpiece while the other output was connected to the tool, both of them were insulated from the machine, and there was a 1000 Ohm resistor in circuit to limit the electric current. The insert connected with the anode of power supply was labeled "+" and when the insert was connected to the cathode of the power supply was labeled as " $\quad$-The currents applied were $+1 \mathrm{~V},+5 \mathrm{~V},+10 \mathrm{~V}$ and $-1 \mathrm{~V},-5 \mathrm{~V},-10 \mathrm{~V}$.

The tool wear tests was carried out with a $0.1 \mathrm{~mm}$ depth of cut at $60 \mathrm{~m} / \mathrm{min}$ cutting speed and 0.1 $\mathrm{mm} / \mathrm{rev}$ feed. The tests were stopped after 10, 30, 60 and 90 second to measure insert flank wear using an optical microscope.

\section{Results and discussion}

The effect of externally applied voltage on tool flank wear was shown in Table 4. There were obviously adhesive wear and abrasive wear.The flank wear changed in different voltage condition. It means that the direction of current flow affected tool wear. The effect of electric current on tool wear rate is shown in Fig. 4.

Table 4 The effect of the voltage on insert flank wear

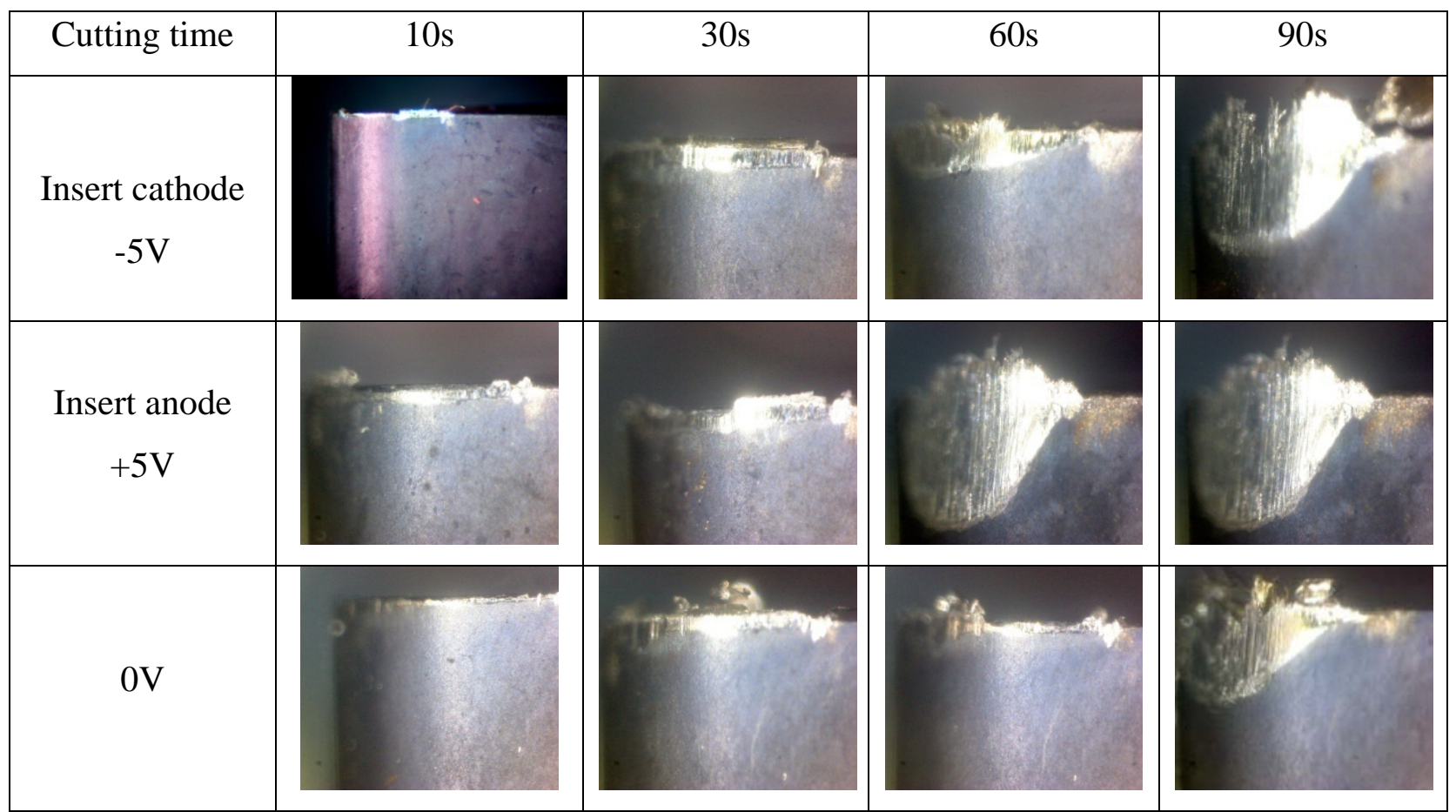

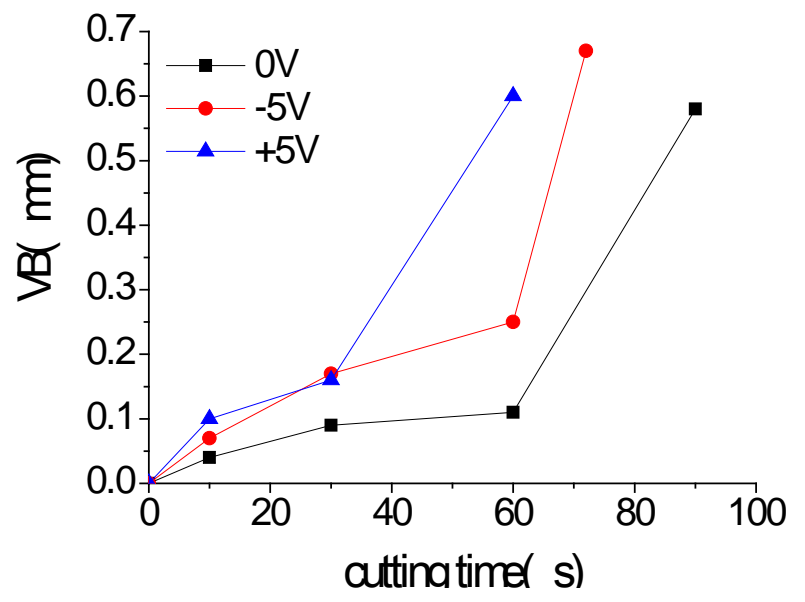

Fig.4 The effect of the voltage on insert flank wear 
Fig. 4 shows flank wear of inserts at different applied voltage as a function of cutting time with a $0.1 \mathrm{~mm}$ depth of cut at $66 \mathrm{~m} / \mathrm{min}$ cutting speed and $0.1 \mathrm{~mm} / \mathrm{rev}$ feed. Generally, the wear of insert increased as cutting time increased. When the insert was anode, the insert wear was higher than when the insert was cathode and also higher than the condition when no current passed, the wear was least when the insert was no current passed through the contact.

The effect of applied voltage on tool wear rate is shown in Fig. 5.

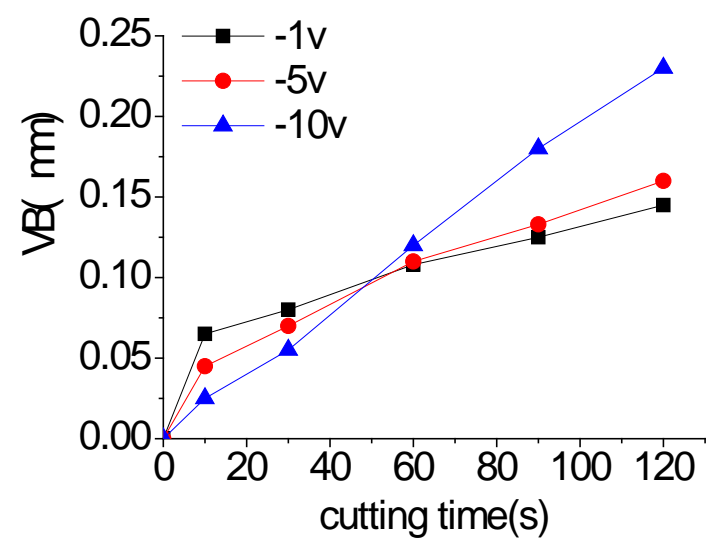

a)tool cathode

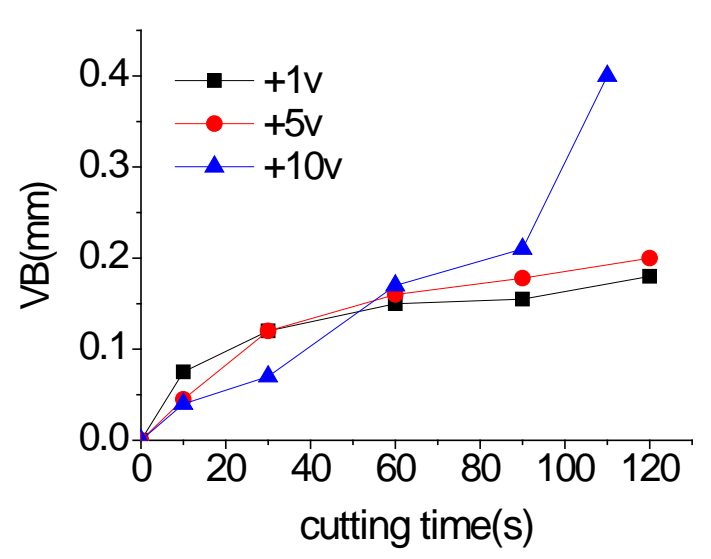

b)tool anode

Fig.5 Effect of applied voltage on flank wear

Fig. 5 shows flank wear at different applied voltage $1 \mathrm{~V}, 5 \mathrm{~V}$ and $10 \mathrm{~V}$ with a $0.1 \mathrm{~mm}$ depth of cut at $54.7 \mathrm{~m} / \mathrm{min}$ cutting speed and $0.1 \mathrm{~mm} / \mathrm{rev}$ feed. It showed that insert wear increased as cutting time increased and changing the voltage affect insert wear significantly. When the insert was cathode, the insert wear was lower than when the insert was anode. Within 50 seconds at the start, the lower the voltage, the faster the tool wear, after 60 seconds, the insert wear increased as applied voltage increased.

\section{Summary}

The tool wear tests were carried out to investigate the effect of an externally applied voltage on insert flank wear in turning of Ni-based superalloy GH4169 with coated carbide tool YBG202. The investigation provided some conclusions as follows:

(1)The applied voltage affected the tool wear. When the insert was cathode, the insert wear was lower than when the insert was anode and the insert wear increased as applied voltage increased. When the insert was no externally voltage applied, the wear was least.

(2)The applied voltage significantly accelerated the tool wear due to serious adhesive and abrasive wear,so it should try to avoid applied voltage when cutting nickel-based superalloy in order to reduce tool wear and increase machining efficiency.

\section{Acknowledgement}

This research reported in the paper is financially supported by Natural Science Foundation of Jiangsu Province, China (BK20140247) and Jiangsu province university students' innovation and entrepreneurship training program (201410294041X). The Corresponding author of this paper is Fusheng Ni.

\section{References}

[1] E. O. Ezugwu, J. Bonney and Y. Tamane. Journal of Materials Processing Technology, 134 (2003): 233-253

[2]A.K. Gangopadhyay, M. Peck, S. Simko. Tribol. Trans. 45(2002):302-309. 
[3] Arup Gangopadhyay, Gary Barber, Han Zhao. Wear. 260(2006): 549-553

[4]Y. Yamamoto, B. Ono, A. Ura. Lubr. Sci. 8 (1996):199-207.

[5]Y.V. Baranov. Materials Science and Engineering A. 287 (2000):288-300

[6] M M Mahmoud1,M K Mohamed, and W Y Ali1. Proc. IMechE Part J: J. Engineering Tribology. 224 (2010):73-79 